\title{
Energy Management Micro Grid using Hybrid De Algorithm with Genetic Algorithm
}

\author{
Anil Kumar P. G., P. Aruna Jeyanthy, D. Devaraj
}

\begin{abstract}
- this paper evaluates hybrid differential evolution algorithm and genetic algorithm of LAMG is used to solving the medium scale mixed integer programming problems. Hybrid $G A$ and DE algorithm is implemented in Local place Micro grids. LPMG and the required need of power and choose more power plants with power production with the help of Genetic algorithm. Genetic algorithm can be introduced with local place micro grid and select any one of the power plant. In this DEA implemented the local place MG, then survey period is one day. Last calculation shows which time or hour produce more power and sold out power in nearest city area electricity board. DE algorithm determine the one day power survey and Genetic algorithm choose more hour and select any one of the hour for better power production. The hybrid DEA and GA is to maintain choosing and selecting of better power production. So our project aim is choose more hour and select any one of the hour for better power production. This hybrid is use $\mathrm{DE}$ and $\mathrm{GA}$ is to maintain the real and reactive power of any power plant
\end{abstract}

Keywords- Local place micro grid (LPMG), Local place energy resources (LPERs), Differential evolution algorithm $(D E A)$, Genetic algorithm $(G A)$ and Electricity $(E B)$.

\section{INTRODUCTION}

GA is one of the most commonly used evolutiory algorithm for solving optimization problem[1], But principle of DE is used to find the true value and analysing true value[6]. In hybrid GA and DEA is maintain the best power production in micro grid[12]. GA select more power plants connected in micro grid[2,3]. But DE select best one[6]. Selection[7], cross-over[8], mutations[9] and fitness solutions[10] are included in GA. DE avoid the drawbacks of optimization technique[11].

\section{SYSTEM COMPONENTS}

A Solar modelling

At the time of max.output from solar panel. maximum power point output ( MPPT ) is,

$\mathrm{Qpv}=\mathrm{Vmpp} * \mathrm{Impp}$

$$
\text { Vmpp }=\text { Vmpp,refr } * \text { Voct }(T p-T p, \text { refr })
$$$$
\text { Impp }=\text { Impp,refr } * \text { Isct,refr }(\mathrm{Tp}-\mathrm{Tp}, \text { refr })
$$

let the working temperature of panel $\mathrm{Tp}$ given by:

$$
\mathrm{Tp}(\mathrm{t})=\mathrm{Ta}(\mathrm{t})+\mathrm{GT}
$$

Where, $\mathrm{Ta}(\mathrm{t})$ is the ambient temperature of panel in $\left({ }^{\circ} \mathrm{C}\right)$, NOCT is the Nominal Operating Cell Temperature for solar irradiation of $500 \mathrm{~W} / \mathrm{m} 2$ and $20^{\circ} \mathrm{C}$ temperature, and GT be avg. of daily solar irradiation (W/m2).

Revised Manuscript Received on December 15, 2019.

Anil Kumar P. G., Assistant Professor, Department of Electrical \& Electronics Engineering, Kalasalingam University (Tamil Nadu) India.

Prof. P. ArunaJeyanthy Department of Electrical \& Electronics Engineering, Kalasalingam University (Tamil Nadu) India.

Prof. D. Devaraj, Faculty, Department of Electrical \& Electronics Engineering, Kalasalingam University (Tamil Nadu) India.

\section{B. Wind Turbine}

The wind turbines in WE systems are connected to gear box. The gear box is an electrical- mechanical interface.

gear box output is given to the permanent magnet synchronous generator (PMSG), which will produces AC output.Thetheoretical power of wind stream in relationship between the wind power and wind speed $\mathrm{Q}$ is determined by

$$
\mathrm{Q}=0.0 \mathrm{Pav}^{3} \mathrm{~W}
$$

For wind energy subsystem: efficiency be 0.45 ; height at which wind turbine located in $10 \mathrm{~m}$.let Radius be $30 \mathrm{~m}$; RHO factor $(\rho)$ is $1.225 \mathrm{~kg} / \mathrm{m} 3$; number of wind turbines: 1 ; height of wind turbine is $60 \mathrm{~m}$;for only a single wind turbine roughness factor be 0.15 . and the Generated power can be supplied to a load consists 50 domestic consumer in average about $20 \mathrm{kWh} /$ day, so the total power demand in avg. would be $1 \mathrm{MWh} /$ day or $365 \mathrm{MWh} /$ year. Size of wind turbine and PV array can be determined basedon assumption that each of every 2 units can able to produce more than $50 \%$ of the power demand.

\section{Fuel Cell}

The fuel cells output in DC electricity, which can be regulated using a DC/DC converter. This DC power can then be fed to the DC bus, which can be used to charge UPS or provide power to home using an inverter.

The considered fuel cell stack is a $\mathrm{H} 2 / \mathrm{O} 2$ then operated and maximum power and nernst form is written by Nernst $=1.229-.85^{*} 10^{\wedge}-3(\mathrm{~T}$ -

$293.15)+4.3085^{*} 10^{\wedge} 5 \mathrm{~T}(\ln \mathrm{Ph} 2+.5 \ln \mathrm{Po} 2)$

Where $\mathrm{P}$ is the effective pressure in atm. and $\mathrm{T}$ is the

temperature in Kelvin.

The consumption of hydrogen during a period of one hour at rated power $\mathrm{Pfc} \mathrm{kW}$ is given by,

where,

$$
\mathrm{HYfc}=[(\mathrm{Qfc} * 3600) /(2 \mathrm{Vfc} * \mathrm{~F})](7)
$$

HYfc = the amount of hydrogen consumed by FC

Qfc = output power of FC

$\mathrm{Vfc}=$ voltage output of $\mathrm{FC}$ 


\section{Energy Management Micro Grid using Hybrid De Algorithm with Genetic Algorithm}

\section{MG ARCHITECTURE CELL MODELLING}

LPMG is a integration of various units. It consists of DG unit energy, storage units, controller unit and conventional loads. DG unit again comprise of various micro generating devices. LPMG modelling varies from one Configuration to other depending on the components used.

LPMG Small scale ranging from 4kw-10000kw.In this LPMG solves many problems existing power systems network.LPMG has maintain the demand supply balance and lack of reliability

LPMG energymanagement, system expression is

$$
=\min \sum_{t=1}^{T}\left[\sum_{g=1}^{G}\left(\begin{array}{c}
E \\
D g t
\end{array}+\begin{array}{c}
R \\
D g t
\end{array}\right)+{ }_{D t}^{R E S}+\sum_{d=1}^{D} \underset{D d t}{D R}\right]
$$

Where,

$$
D_{g t}^{E}=a_{g} \cdot U g t+b_{g} \cdot P_{g t}+C_{g}^{\sup _{g}} \cdot Y_{g t}+C_{g}^{s d n} \cdot Z_{g t}
$$

(9)

$$
\text { Bt€T, Bg€G }
$$

$$
\stackrel{R}{D g t}=\sum_{q \in Q} \sum_{k \in K} \begin{gathered}
R \\
C g q k \cdot R
\end{gathered} \stackrel{c t}{R g k r}
$$

$$
D^{R E S}=d w \cdot \sum_{w=1}^{W} \underset{P_{w t}}{f}+d v \cdot \sum_{v=1}^{v} \underset{P v t}{f} \quad \mathrm{Bt€ \textrm {T }}
$$

$$
\stackrel{D R}{D d t}=\sum_{n=1}^{N} d d n
$$

Genetic algorithm is the one of the most commonly used evolutiory algorithm for solving optimization problem. Principle of GA is natural evolution.

Our aim of this natural evolution is to maximize the resources and select best[1], So we are getting best solution.GA require good knowledge about problem being solved. In this GA is implemented easily and GA ability to capture multiple optimal solution in single run. Population size of Control parameter of

GA is 50-100. Generation of GA[1] is 20-200. Cross over prability[7] is $0.6-0.7$ and mutation probability[8]y is 0.001 0.01 . The core of GA is create more energy, formulation of fitness function is used to determine individual power sources with respect to the problem. The main aim this paper indicate GA is applied for DE.

\section{Hybrid GA and DE}

To apply GA and DE for coding problem is a objective function. Every hour produce many possible solution of power production and take best solution[11]. The basic thing of hybrid GA and DE select them fitting them and used better solution. The hybrid GA and DE is a optimization problem and best objective is minimize the cost, maximize the profit, choose more and select one. Another way of hybrid operation of GA and DE is meeting the demand in electrical energy at minimum fuel cost, Design of electrical works and component with minimum manufacturing cost. In this hybrid operation is not affected by less no parameter in $\mathrm{DE}$ and large no parameter in GA.Faster manner convergence character of DE and shorter convergence character of GA is not affected for hybrid operation[6]. Because DE is simplified algorithm of GA.

\section{Objective Function}

Objective function DEA and GA maintain which hour which plant produce best solution of power. So the consumer getting the power in needed time.

The real power of LPMG is denoted by the following equation

$\mathrm{A}=\mathrm{V} 1 \wedge 2 \cos \mathrm{Q}-\mathrm{B} 1 \mathrm{~V} 2 / \mathrm{Z} \cos (\mathrm{P}+\mathrm{Q})$

The Reactive power of LPMG is denoted by the following equation

$\mathrm{B}=\mathrm{B} 1 \wedge 2 \cos \mathrm{Q}-\mathrm{B} 1 \mathrm{~B} 2 / \mathrm{Z} \sin (\mathrm{P}+\mathrm{Q})$ 
International Journal of Innovative Technology and Exploring Engineering (IJITEE) ISSN: 2278-3075, Volume-9 Issue-2S2, December 2019

Table 1. Total cost for 1-12 hour power calculation

\begin{tabular}{|c|c|c|c|c|c|c|c|c|c|c|c|c|}
\hline & 1 am & $2 \mathrm{am}$ & 3am & 4am & 5am & 6am & $7 \mathrm{am}$ & $8 a m$ & 9am & 10am & 11am & 12am \\
\hline $\begin{array}{l}\text { Real power } \\
\text { of wind }(\mathrm{kw})\end{array}$ & 1.1111 & 1.2111 & 1.31111 & 1.42123 & 1.5432 & 1.687765 & 1.77654 & 1.87654 & 1.98765 .987 & 2.111 & 2.5654 & 3.987 \\
\hline $\begin{array}{cc}\text { Real power } & \\
\text { of } & \text { solar } \\
& \\
(\mathrm{kw}) & \end{array}$ & 0 & 0 & 0 & 0 & 0 & 0.111 & 0.2432 & 0.3876 & 0.487765 & 0.8876 & 1.876 & 5.9999 \\
\hline $\begin{array}{l}\text { Real power } \\
\text { of fuel cell } \\
(\mathrm{kw})\end{array}$ & 5,212 & 5.876 & 5.987 & 5.098 & 5.9998 & 5.876 & 5.8765 & 5.99876 & 5.987 & 5.987 & 5.987 & 5.999 \\
\hline $\begin{array}{l}\text { sold } \\
\text { power(kw) }\end{array}$ & 1 & 1 & 1 & 1 & 1.1 & 1.2 & 1.3 & 1.4 & 1.5 & 1.6 & 1.6 & 3 \\
\hline $\begin{array}{l}\text { sold } \\
\operatorname{cost}(1 / \mathrm{h})\end{array}$ & 2 & 2.10 & 2.20 & 2.30 & 2.40 & 2.50 & 2.60 & 2.70 & 2.80 & 2.90 & 3 & 5 \\
\hline $\begin{array}{c}\text { purchase } \\
\text { power }(\mathrm{kw}\end{array}$ & 3.1 & 3,05 & 3.05 & 2.9 & 3.0 & 3.0 & 3.0 & 3.0 & 2.5 & 2 & 2 & 0,8 \\
\hline $\begin{array}{l}\text { purchase } \\
\text { cost }(1 / \mathrm{h})\end{array}$ & 5 & 5.10 & 5.05 & 5 & 4.9 & 4.7 & 4.5 & 4.3 & 4.1 & 4 & 3 & 1.9 \\
\hline $\begin{array}{l}\text { Total } \\
\operatorname{cost}(1 / \mathrm{h})\end{array}$ & 2 & 3 & 4 & 4 & 5 & 5.5 & 6 & 6.5 & 6.7 & 6.9 & 7.1 & 9 \\
\hline
\end{tabular}

Table II. Total cost for 12-24 hours power calculation

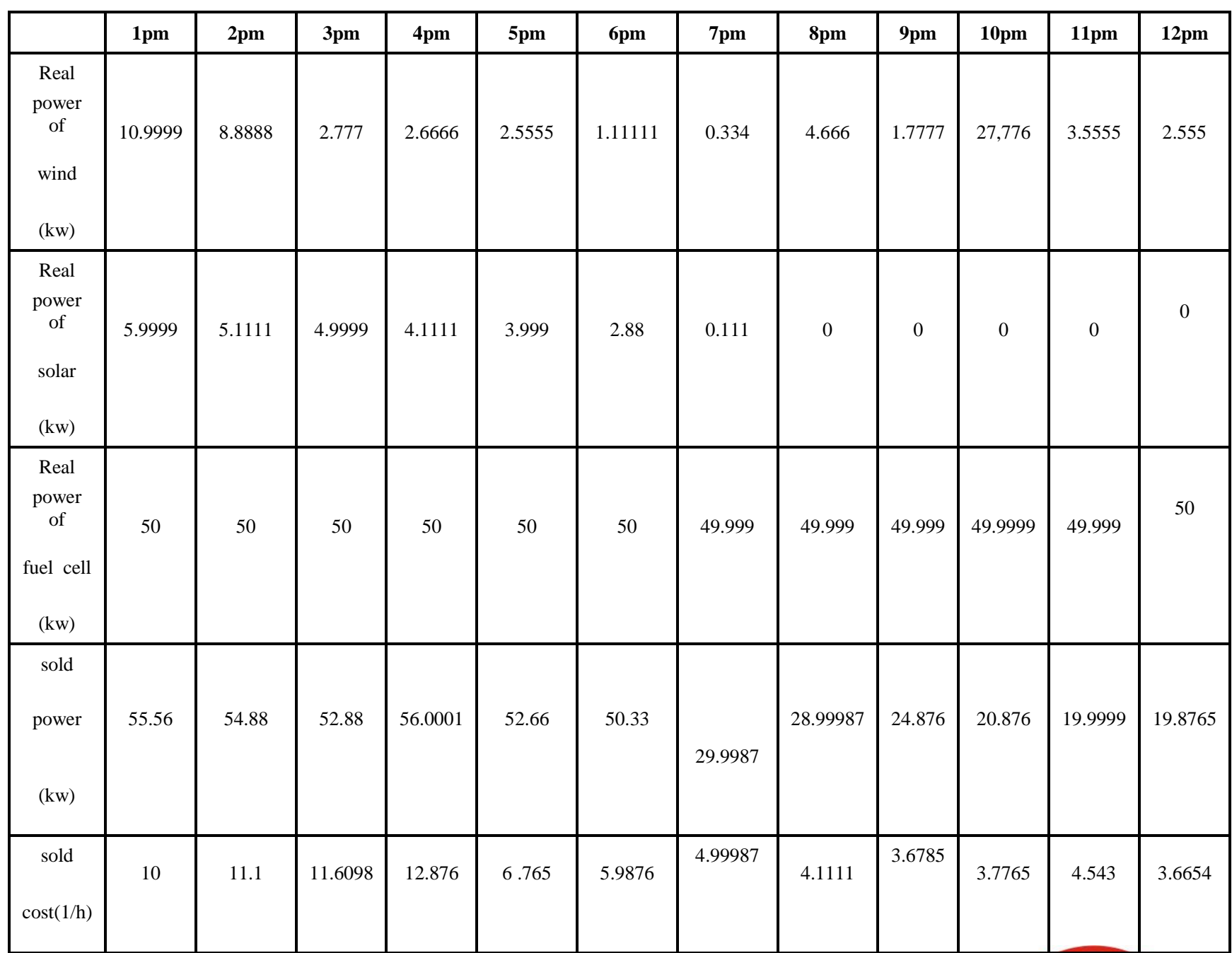




\section{Energy Management Micro Grid using Hybrid De Algorithm with Genetic Algorithm}

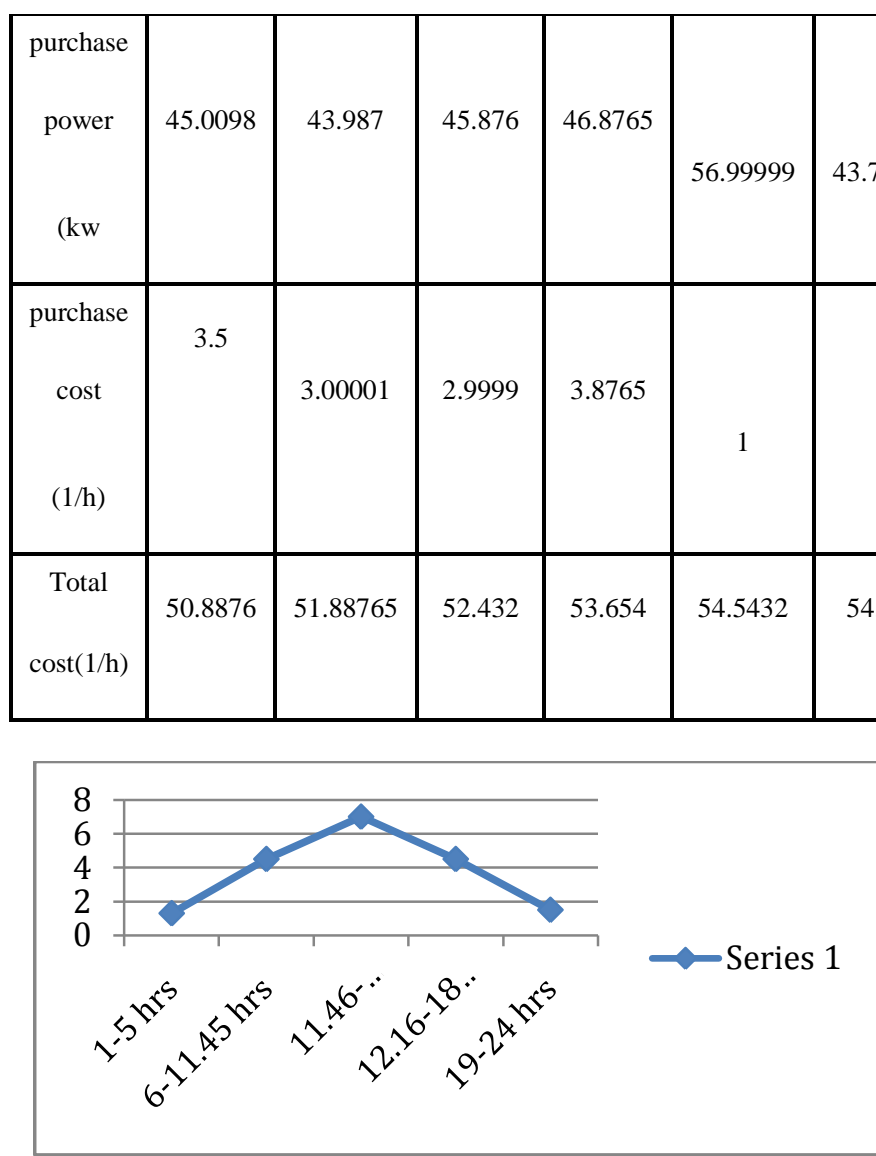

Fig (1)

\section{RESULT FOR PROPOSED SYSTEM}

\begin{tabular}{|c|l|l|l|}
\hline $\begin{array}{l}\text { Time for } \\
\text { power } \\
\text { production }\end{array}$ & $\begin{array}{l}11 \text { '”'o } \\
\text { clock }\end{array}$ & $\begin{array}{l}12 \text { '”o } \\
\text { clock }\end{array}$ & $\begin{array}{l}1 \text { '”'o } \\
\text { clock }\end{array}$ \\
\hline $\begin{array}{c}\text { GA } \\
\text { selection }\end{array}$ & $\checkmark$ & $\checkmark$ & $\checkmark$ \\
\hline $\begin{array}{c}\text { DEA } \\
\text { selection }\end{array}$ & - & $\checkmark$ & - \\
\hline
\end{tabular}

\section{CONCLUSION}

If the Differential evolution algorithm is used for calculate which time LPMG generate more power. In this DEA choose three time is selected. In this DEA determine 11 "o" clock, 12 "o" clock and 1 "0" clock power generation is better for LPMG. GA is used to maintain the any one of the better time of power production. But the combination DEA and GA choose maximum power production time. In the 12 "o" clock better time for power of LPMG GA choose the best power of solar, wind and fuel cell power production

\section{REFERENCES}

[1] Man, K.F, Tang, K.S \&Kwong. S "Genetic algorithm concepts and applications, IEEE Tranactions on industrial Electronics, 43(5),519 534,doi $10.1109 / 41538609$

[2] IEEE Colloquium on "Genetic . Algorithm for control Systems Engineering 9Digest No 1993/130)
[3] E.G.Talbi. T Munten IEEE colloquium on "Genetic Algorithm for control systems Engineering"1993.

[4] A. Hernandez- Aramburo, T. C. Green, and N. Mugniot, "Fuel consumption minimization of a microgrid," IEEETrans. Ind. Appl., vol. 41, no. 3, pp. 673-681, May/Jun.2005

[5] N. Ming, H. Wei, G. Jiahuan, and S. Ling, "Research on economic operation of grid-connected microgrid," PowerSyst. Technol., vol. 34 no. 11, pp. $38-42,2010$

[6] Jiang Xinzi; Tang Kezong 2007 chinese Chinese control Conferance on 2006 on "Hybrid Algorithm combing Ant ColongOptization Algorithm with Ceneti Algorithm",

[7] Alessandra Parisio, EvangelosRikos, Luigi Glielmo,"

Stochastic model predictive control for economic / environmental operation management of micro grids. An experimental case study"13 may 2016.

[10] P.Kaelo and M.M.Ali, "A numerical study of some modified differential algorithms" Eur. J.Oper, Ees,vol,169,pp 11761184,20006 .

[8] Levron, Yoash, Guerrero, Joseph M Beck, Yuval, "Optimal power flow in micro grids with Energy storage".

[9] D.E.Golberg. and Richardson "Genetic algorithm with shairing for multimodel function optimization " in proc

2 ndconference, Genetic algorithms, Genetic Algorithm and Their Applications Camgbridge MA 1987.

[10] S.KannanS.M.R.Silochannel and N.P. Padhy ,:Applications and comparision of methaheuristic techniques to generation expansion planning problem ,'IEEE Trans Power Syst, vol20,no 2,pp,668-74, May 2005.

[11] X.D. Li,"'Efficient differential evolution using speciation for multimodel function optimization" in Genetic And evolutionary Computation Conf- , ,GECCO 05. Washinton , DC, 2005.

[12] IEEE transations on neural network and learning systems, Ganesh kumar, Ratnesh k Sharma, prajwal and AfshinAhmadi "DynamicEnergy Management System for a smart micro grid

[13] Miranda and N.Fonseca "EPSO - evolutionry optimization particle swaem optimization, a new algorithm with applications in power systems" in proc IEEE Power EngSoc Summer meeting, Chicago, 2012.

[14] L.J.Fogel , A.J. Owens, and M.J.Walsh, "Artifigual Intelligence Through Simulated evoulation,” New York:Willey 1996.

\section{AUTHORS PROFILE}

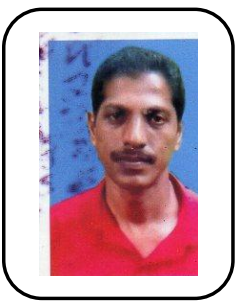

Anil Kumar P. G. completed B-tech in Electrical and Electronics engineering in 2005 from Ann University., and ME in 2013 Power systems from Anna University. $\mathrm{He}$ is working as assistan professor in Kottayam Institute of Technology and science 2013 .Currently pursing $\mathrm{PhD}$ in Energy management in microgrid at Kalasalingam University Tamil Nadu. 


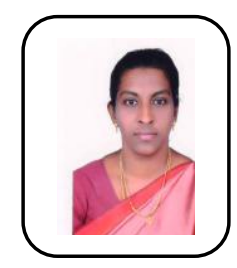

Prof. P. ArunaJeyanthy completed B.E in Electrical and Electronics Engineering from Madurai Kamaraj University and M.E in power systems from Annamalai University, also completed Ph.D in from Anna University,Chennai. She is currently working in Electrical and Electronics Engineering department, Kalasalingam University.. She has published papers in 29 international journals. She has received many numbers of awards, Prizes and Honors for paper presentations and her valuable services in this field.

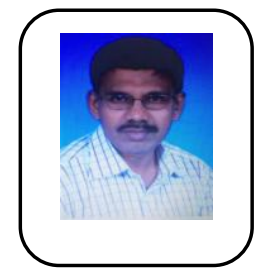

Prof. D. Devaraj Completed B.E and M.E in Electrical \& Electronics Engineering and Powe System Engineering in the year 1992 and 1994, respectively, from Thiagarajar College of Engineering, Madurai. From 1994 to 1997, he worked as a Lecturer in ArulmiguKalasalingam College of Engineering, Krishnankoil. He obtained his Ph.D degree from IIT Madras, Chennai in the year 2001. Since 2001, he is working as a faculty in the Electrical \& Electronics Engineering department of Kalasalingam University. He has organized 6 Conferences, 8 Seminars and conducted 10 workshops. He has published 105 papers in Journals and presented 250 papers in conferences. He has chaired 15 technical sessions in various National and International Conferences. He has Supervised 15 Ph.D, 2 M.S and 25 M.E thesis. Presently, he is guiding $8 \mathrm{Ph} . \mathrm{D}$ scholars. His research interest includes Power system security, Voltage stability, Smart grid, Evolutionary algorithms, Neural network and Data Mining. He is a senior member IEEE. Presently, he is the Dean - Academic, Senior Professor/EEE at Kalasalingam University, Krishnankoil 